\title{
3Dim experimental investigation of linear viscoelastic properties of bituminous mixtures
}

\author{
Daniel Perraton 1 - Hervé Di Benedetto - Cédric Sauzéat • \\ Bernhard Hofko • Andrea Graziani • Quang Tuan Nguyen · \\ Simon Pouget $\cdot$ Lily D. Poulikakos $\cdot$ Nouffou Tapsoba $\cdot$ James Grenfell
}

Received: 3 September 2015/Accepted: 10 February 2016/Published online: 3 March 2016

(C) RILEM 2016

\begin{abstract}
As part of RILEM TC 237-SIB, TG3 performed a Round Robin Test to evaluate the capacity to measure Poisson's ratio of an asphalt mixture in the laboratory and to check whether it could be considered as an isotropic property. Five laboratories located in five different countries took part in the testing program. This paper presents the different techniques used by the laboratories, reports the measured Poisson's ratios and comments upon the differences found between the results. Sinusoidal or haversine loading either in tension-compression or pure compression was applied to the specimens over a range of frequencies and temperatures. During the loading both the axial and radial strains were monitored to allow the complex Young's modulus and the complex Poisson's ratios to be calculated. It was found
\end{abstract}

D. Perraton $(\square)$

University of Québec, ETS, 1100 Notre-Dame Ouest,

Montreal, QC H3C 1K3, Canada

e-mail: daniel.perraton@etsmtl.ca

H. Di Benedetto · N. Tapsoba

University of Lyon, ENTPE - LTDS, Vaulx-en-Velin,

France

C. Sauzéat

ENTPE - LTDS, Vaulx-en-Velin, France

B. Hofko

Vienna University of Technology, Vienna, Austria

A. Graziani

Università Politecnica delle Marche, Ancona, Italy that the complex Young's modulus and the complex Poisson's ratios were very close in the Black Diagrams, but diverge sharply in the Cole-Cole plots. It was observed that the maximum difference between the complex Poisson's ratio in direction 2 and direction 3 is less than 0.05 . It would appear that this difference is more related to measurement deviation than anisotropy of the material. Some differences were observed in the master curves of complex Young's modulus and complex Poisson's ratio obtained from the five laboratories; however these differences could in most cases be explained by temperature differences. It was concluded that within the linear viscoelastic range (small strains) the results from the different laboratories show similar rheological behavior and the material response follows the same trend.

Q. T. Nguyen

University of Transport and Communications, Hanoi,

Vietnam

Q. T. Nguyen

University of Lyon, ENTPE, Lyon, France

S. Pouget

EIFFAGE Travaux Publics, Paris, France

L. D. Poulikakos

EMPA, Swiss Federal Laboratories for Materials Science and Technology, Dübendorf, Switzerland

J. Grenfell

University of Nottingham, Nottingham, UK 
Keywords Complex Young's modulus · Complex Poisson's ratio - 3Dim behaviour - Viscoelastic property $\cdot$ Bituminous mixture $\cdot$ Modeling

\section{Introduction}

Stress-strain fields that develop in a pavement structure under traffic loadings and environmental conditions are three-dimensional. To determine the resultant strains in the pavement system, two independent material properties are required if the material is isotropic: (1) the Young's modulus and, (2) the Poisson's ratio. Therefore, the mechanical characterization of pavement materials should not be limited to a single one-dimensional (1D) property. In particular, for small deformation, bituminous mixtures are considered in most cases as linear viscoelastic (LVE) and isotropic materials. This means that their threedimensional (3D) properties can be characterized through the simultaneous measurements of two timeor frequency- dependent material functions such as the complex Young's modulus $E^{*}$ and the complex Poisson's ratio $v^{*}$.

In pavement design, Poisson's ratio of hot mix asphalt (HMA) is often assumed to be constant though several experimental studies have shown its time (frequency) and temperature dependence [1-13]. Sensitivity analyses were conducted by Maher and Bennert [14] and by Schwartz et al. [15], using the MEPDG software to evaluate how change in the Poisson's ratio of the HMA layers affect distress predictions in a typical pavement structure. The results showed that the HMA Poisson's ratio ranked in the highest sensitivity categories for flexible pavement performance predictions. In particular, a reduction in the Poisson's ratio negatively affects the prediction of the total pavement rutting [16] as well as longitudinal and alligator crack development. To this end, characterization and modelling of the Poisson's ratio of asphalt mixtures is one way to improve pavement damage prediction.

Though in pavement design methods, HMA is considered to behave as an isotropic material, the laydown and compaction process could lead to a preferential orientation of the aggregate skeleton, thus inducing an anisotropic behavior. In particular, the following preferential directions can be recognized: (1) horizontal longitudinal direction (direction 1), (2) vertical direction (direction 2) and, (3) transverse horizontal direction (direction 3).

To reproduce the roller compactor effect on the structural arrangement of an asphalt material placed on the road, different types of compactors were developed to produce HMA slabs in the laboratory. Often, samples used for mechanical investigations are cored in the direction of the compactor wheel displacement (dir 1) to determine the complex Young's modulus. In order to evaluate whether the Poisson's ratio can be considered as an isotropic property, the transversal strains (dir2 and dir3) under axial loading (dir1) must also be measured.

In the framework of the RILEM TC 237-SIB TG3, a Round Robin Test (RRT) was performed in order to evaluate the capability of the different labs to measure the Poisson's ratio of an asphalt mixture in the laboratory and to check whether it could be considered as an isotropic property. Five laboratories located in 5 countries were involved in the testing program. The paper focused on presenting the different techniques used by the laboratories and on reporting the measured Poisson's ratios and differences in the test results between the laboratories.

\section{Poisson's ratio for linear viscoelastic materials}

Stress/strain relationships are considered when bituminous mixtures are subjected to cyclic loading. In the considered experiments, a sinusoidal (tension/compression) or haversine (compression) is applied to cylindrical specimens at different temperatures and loading frequencies. The axial strain amplitude should be small enough in order to ensure that the behavior remains within the linear domain [17-19].

From axial stress $\left(\sigma_{1}\right)$, axial strain $\left(\varepsilon_{1}\right)$ and radial strain in directions $2\left(\varepsilon_{2}\right)$ and $3\left(\varepsilon_{3}\right)$ values given in Eqs. 1-3, it is possible to calculate the complex Young's modulus in the axial direction (dir1) and the complex Poisson's ratios in the two transversal directions (dir2 and dir3 for axial loading in dir1) as expressed by Eqs. 4 and 5 respectively.

Considering only the harmonic, steady-state part of the stress and strain signals, as represented in Fig. 1a, we can write: 
$\varepsilon_{1}(t)=\varepsilon_{01} \sin \left(\omega t+\varphi_{\varepsilon 1}\right)$

$\sigma_{1}(t)=\sigma_{01} \sin \left(\omega t+\varphi_{\sigma 1}\right)$

$\varepsilon_{i}(t)=\varepsilon_{0 i} \sin \left(\omega t+\varphi_{\varepsilon i}\right)(i=2,3)$

where $\varepsilon_{01}, \varepsilon_{02}, \varepsilon_{03}$ and $\sigma_{01}$ are the axial strain amplitude, the radial strain amplitude in directions 2 and 3 , and the axial stress amplitude, respectively; $\omega=2 \pi f$ is the pulsation (angular frequency) and $\varphi$ is the phase angle that can be used to characterize the time shift between the signals. For a viscoelastic material, since the strain will lag behind the stress, we have $\varphi_{\sigma 1}<\varphi_{\varepsilon 1}$.

It is emphasized that, for conventional materials, contraction/expansion in axial direction (dir1) is accompanied by expansion/contraction in the transverse directions (dir2 and dir3) and therefore axial and transverse strains are, roughly, in counter-phase. In general it is also assumed that contraction/expansion in axial direction reaches it maximum value before expansion/contraction in the transverse directions, which implies negative values for $\varphi_{v i}(i=2,3)$. However, the latter is only a heuristic assumption, which is subjected to experimental verification [20].

(a)

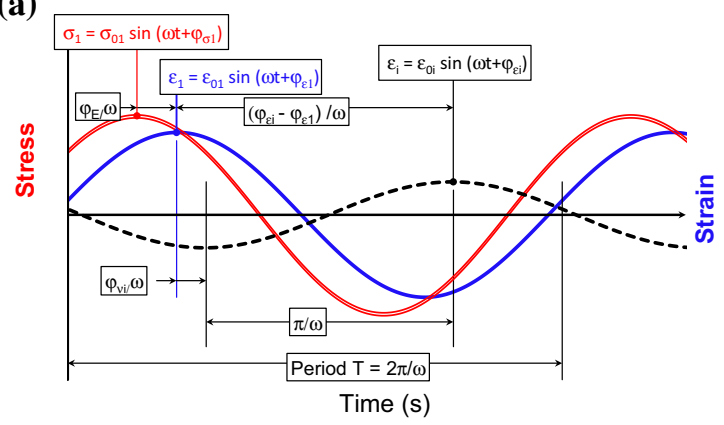

(b)

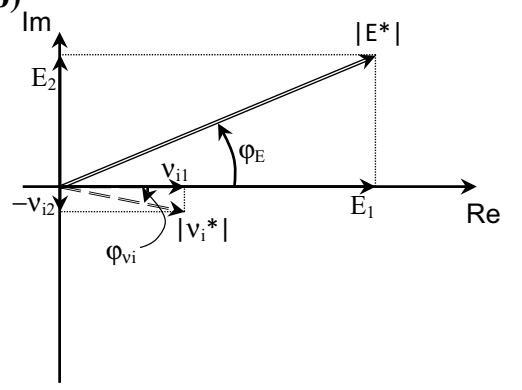

Fig. 1 Schematic representation of parameters considered for rheological characterization: a stress and strain signals in the time domain, and $\mathbf{b} E^{*}$ and $v^{*}$ in complex plane
Considering complex exponential notation, the complex Young's modulus is represented in the complex plane as shown in Fig. 1b, and is given by:

$E^{*}=\frac{\sigma_{01}}{\varepsilon_{01}} e^{\mathrm{j}\left(\varphi_{\sigma 1}-\varphi_{\varepsilon 1}\right)}=\left|E^{*}\right| e^{\mathrm{j} \varphi_{E}}$

where $\mathrm{j}$ is the complex number defined by $\mathrm{j}^{2}=-1$ and $\varphi_{\mathrm{E}}>0$ due to viscous damping (i.e. $\varphi_{\sigma 1}<\varphi_{\varepsilon 1}$ ).

The complex Poisson's ratios for directions 2 and 3 are calculated as follows:

$$
\begin{aligned}
v_{i}^{*} & =-\frac{\varepsilon_{0 i}}{\varepsilon_{01}} e^{\mathrm{j}\left(\varphi_{\varepsilon i}-\varphi_{\varepsilon 1}\right)}=\frac{\varepsilon_{0 i}}{\varepsilon_{01}} e^{\mathrm{j}\left(\varphi_{\varepsilon i}-\varphi_{\varepsilon 1}-\pi\right)} \\
& =\left|v_{i}^{*}\right| e^{\mathrm{j}\left(\varphi_{v i}\right)}(i=2,3)
\end{aligned}
$$

$\varphi_{v i}=\varphi_{\varepsilon i}-\varphi_{\varepsilon 1}-\pi$

Following this notation, as long as $\varphi_{\varepsilon 1}<\varphi_{\varepsilon i}-\pi$, one should obtain $\varphi_{v}<0$.

Furthermore, $\varphi_{E}$ is the phase angle between the axial stress and the mean axial strain, and $\varphi_{v 2}, \varphi_{v 3}$ were the phase angles between the opposite of radial strains in directions 2 and 3 and the axial strain. $\left|E^{*}\right|$, $\left|v_{2}^{*}\right|$ and $\left|v_{3}^{*}\right|$ are the norms of the complex Young's modulus and of the complex Poisson's ratios in directions 2 and 3.

\section{Experimental program}

In the framework of the RILEM TC 237-SIB TG3, a Round Robin Test (RRT) has been performed to measure complex Poisson's ratio measurements. The five laboratories involved in the RRT testing program were: University of Lyon/ENTPE (France), University Politecnica delle Marche (Italy), University of Québec/ÉTS (Canada), Vienna University of Technology (Austria), EMPA (Switzerland). All Bituminous mixtures slabs $\left(120 \times 400 \times 600 \mathrm{~mm}^{3}\right)$ were compacted in the laboratory at the EIFFAGE Travaux Publics Company.

\subsection{Tested material}

A bituminous mixture designated as GB3 (GB stands for "Grave Bitume" in French) was used in the RRT. This mixture is commonly used for base course construction in France. The GB3 bituminous mixture was produced in the laboratory in accordance with the EN 12697-35 Standard. A nominal aggregate size 
0/14 mm with high quality, fully-crushed aggregates and a pure bitumen 35/50 Pen grade were used. The bitumen content was $4.5 \%$ by weight of the mixture. Figure 2 presents the aggregate grading curve of the GB3 bituminous mixture. The maximum specific gravity of the GB3 mix $\left(G_{\mathrm{mm}}\right)$ was 2.670 .

\subsection{Sample preparation}

Immediately following laboratory mixing at $160{ }^{\circ} \mathrm{C}$ in a thermo-regulated mixer, the full batch was transferred from the mixer into a steel pan, covered and placed in a preheated oven at $145^{\circ} \mathrm{C}$. After a curing time of $2 \mathrm{~h}$, the material was manually homogenized prior to compaction with a French LPC (Laboratoire des Ponts et Chaussées) wheel compactor (Fig. 3b), according to the European standard [EN 12697$33: 2003+$ A1 [21, 22].

After a rest period of 24 to $48 \mathrm{~h}$, asphalt slabs were removed from the mold and cut into two parts before a half slab was shipped to each laboratory for testing.

Cylindrical specimens were cored (Fig. 3a) from the provided slab section by each local laboratory staff. Core samples were then trimmed to the target height in accordance with the specific setup of each laboratory. Prior to coring the samples in the provided slab section, each laboratory marked the cored section in order to identify the location of directions 2 and 3 on the plane surface of the core sample for testing. The preferential material directions (1,2 and 3) are indicated in Fig. 3a. Table 1 presents the geometrical characteristics of the tested specimens and the location of the laboratory.

All tested samples were cored 3-6 months after slabs were produced and complex Young's modulus

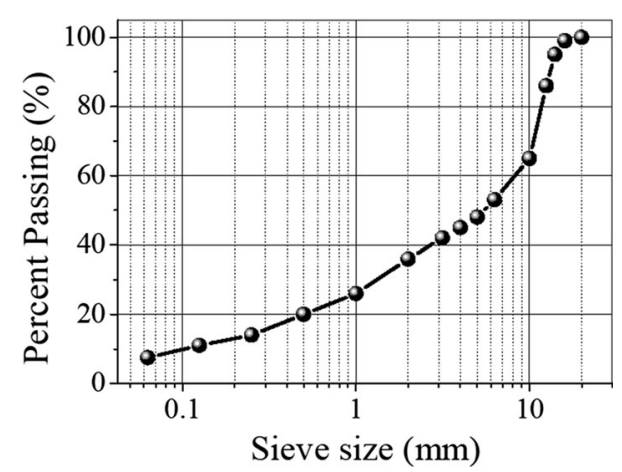

Fig. 2 Grading curve of the tested GB3 bituminous mixture measurements, as well as complex Poisson's ratio measurements, were performed 6-18 months after slabs were delivered.

\subsection{Test equipment and measurement setup}

All laboratories involved in the RRT program used their own setup and instrumentation to determine the stress and strain values applied to the samples during testing. Figure 4 shows the setups used by each laboratory involved in the RRT. The following sections detail setup and procedure used by each laboratory to determine the complex Young's moduli and complex Poisson's ratios.

\subsubsection{Lab1}

The sinusoidal loading in tension and compression was applied to the glued specimen along direction 1 using a hydraulic press having a maximum load capacity of $\pm 25 \mathrm{kN}$ and $a \pm 50 \mathrm{~mm}$ axial stroke. The axial strain was measured on the middle part of the specimen using three extensometers (Fig. 4a) located $120^{\circ}$ around the specimen, with an initial length of $75 \mathrm{~mm}$. Radial strains were measured in direction 2 and direction 3 using 4 non-contact sensors (NCS). For each direction, two non-contact sensors were set in opposite directions on a sample diameter and aimed at two aluminium targets glued on the sample (Fig. 4a). A thermal chamber was used to control the temperature of the specimen during the test. The temperature was measured with a thermal gage (PT100 surface temperature probe) glued on the specimen surface.

The cylindrical specimen $(75 \mathrm{~mm}$ in diameter and $140 \mathrm{~mm}$ in length) was loaded at 6 frequencies $(0.03-10 \mathrm{~Hz})$ and 9 temperatures $\left(-25\right.$ to $\left.40{ }^{\circ} \mathrm{C}\right)$. The sinusoidal axial strain $\left(\varepsilon_{1}\right)$ (average of three extensometers) was used for monitoring of the amplitude of axial strain during cyclic loading to assure it was $50 \mu \mathrm{m} / \mathrm{m}$. The number of cycles applied at each frequency was small (less than 100), and as a result, effect of heating due to viscous dissipation [23, 24] were negligible. The axial stress $\left(\sigma_{1}\right)$ was obtained from the load cell signal and radial strains $\left(\varepsilon_{2}\right.$ and $\left.\varepsilon_{3}\right)$ were deduced from the two pairs of non-contact transducers. Sinusoidal curves of strain and stress were fitted to the experimental data $\left(\varepsilon_{1}, \sigma_{1}, \varepsilon_{2}\right.$ and $\left.\varepsilon_{3}\right)$ and used to calculate the norm and phase angle of the complex Young's modulus $\left(E^{*}\right)$ and complex 
Fig. 3 Schematic representation of the production of a mechanical bituminous mixture specimen obtain from slab; b picture of the French LPC compactor used to produce asphalt bituminous mixture slab test sample: a sketch of the
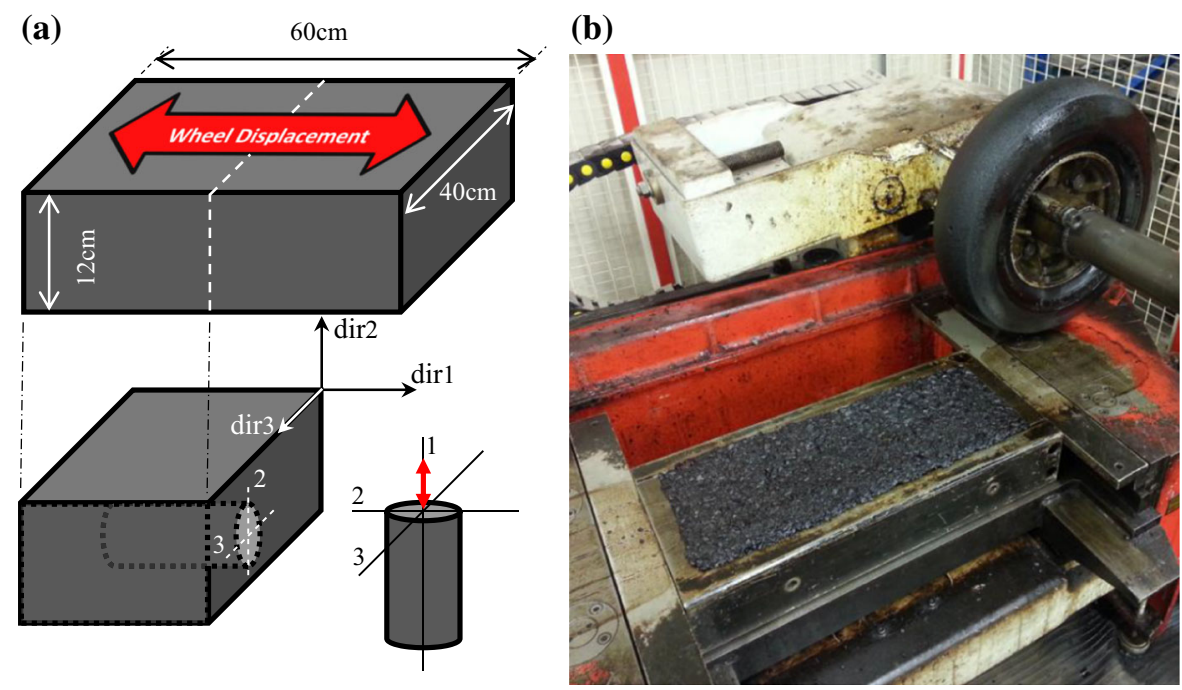

Table 1 Geometrical characteristics of tested specimens $\left(G_{\mathrm{mb}}\right.$ bulk specific gravity; $G_{\mathrm{mm}}$ maximum specific gravity)

$G_{m b}$ water density at $T^{\circ}=$ MVA at $\mathrm{T}^{\circ}, G_{m m}$ water density at $\mathrm{T}^{\circ}=\mathrm{MVR}$ at $\mathrm{T}^{\circ}$

\begin{tabular}{|c|c|c|c|c|c|c|c|}
\hline \multirow[t]{2}{*}{ Name } & \multirow[t]{2}{*}{ Country } & \multirow[t]{2}{*}{ Mass (g) } & \multicolumn{2}{|c|}{ Diameter $(\mathrm{mm})$} & \multirow[t]{2}{*}{$\mathrm{G}_{\mathrm{mb}}$} & \multirow[t]{2}{*}{$\mathrm{G}_{\mathrm{mm}}$} & \multirow[t]{2}{*}{ Void (\%) } \\
\hline & & & Diameter & Height & & & \\
\hline Lab1_sp1 & France & 1572 & 73.8 & 140.9 & 2.610 & 2.670 & 2.3 \\
\hline Lab1_sp2 & France & 1564 & 73.7 & 140.1 & 2.614 & & 2.1 \\
\hline Lab2_sp1 & Italy & 3028 & 92.0 & 175.0 & 2.603 & & 2.5 \\
\hline Lab3_sp1 & Canada & 1375 & 74.0 & 123.0 & 2.615 & & 1.5 \\
\hline Lab4_sp1 & Austria & 3955 & 99.7 & 198.0 & 2.593 & & 2.9 \\
\hline Lab5 sp1 & Switzerland & 3986 & 99.0 & 201.1 & 2.594 & & 2.9 \\
\hline
\end{tabular}

Poisson's ratios ( $v_{2}^{*}$ and $v_{3}^{*}$ ) using Eqs. 1-6. As three extensometers were used for axial strain measurement, sinusoidal strains were first fitted to data for all single extensometers, and mean values of axial amplitudes and phase angles were used as $\varepsilon_{01}$ and $\varphi_{\varepsilon 1}$ in all calculations. The same experimental device is used in $[25,26]$.

\subsubsection{Lab2}

Axial sinusoidal loading (tension-compression) was applied using a servo-hydraulic press with a maximum axial displacement of $100 \mathrm{~mm}$, equipped with a $20 \mathrm{kN}$ force transducer. A thermal chamber was used to control the temperature of the glued specimen during the test.

Three axial and three transverse strains were measured, using three pairs of strain gages glued on the middle part of the specimen. The configuration of the gages is outlined in Fig. 4b. Measuring points are located at $120^{\circ}$ around the specimen, and their position with respect to the compaction direction is outlined in Fig. 4b.

Conventional bonded wire gages with polyester resin backing (TML P60) were used. The gage length was $60 \mathrm{~mm}$ and the nominal resistance was $120 \Omega$. A two-component room-temperature curing polyester adhesive (TML RP-2) was used to glue the strain gages. Moisture and physical protection were made with a $3 \mathrm{~mm}$ covering agent (TML SB tape).

For each sensor, a separate Wheatstone half-bridge circuit was employed to compensate for temperature effects. The second half of the bridge was positioned on a dummy specimen, identical to the active one located within the same thermal chamber. The temperature was measured with a K-type thermocouple positioned inside an additional dummy specimen.

Signal conditioning, bridge compensation and A/D conversion were carried out using a portable HBM Spider8 unit. The HBM Catman Express software was 
(a)

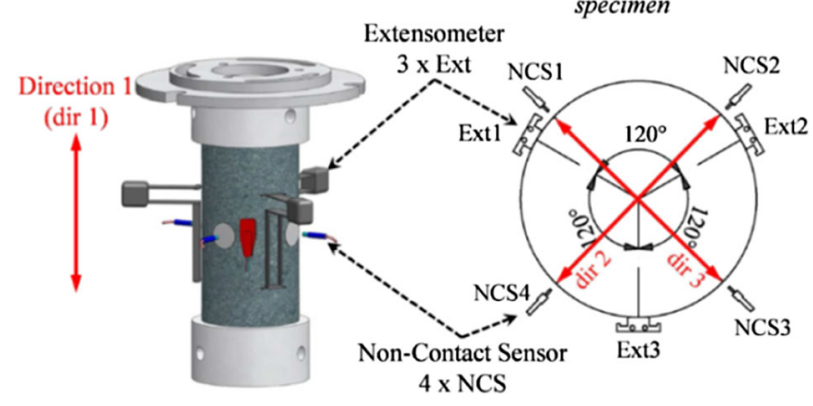

Top view (b)

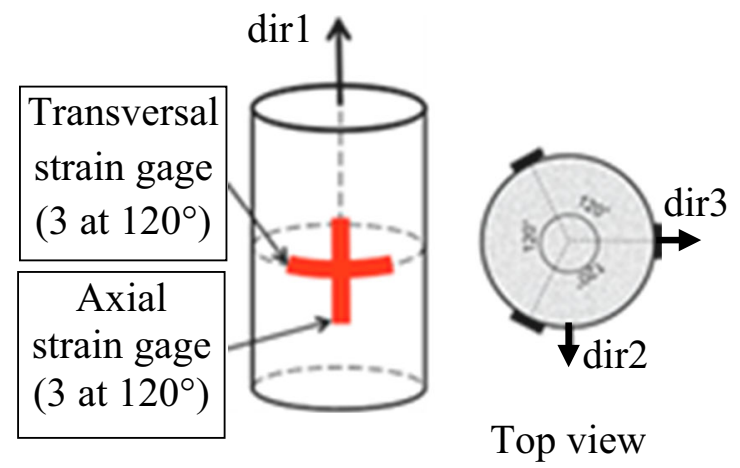

(d)

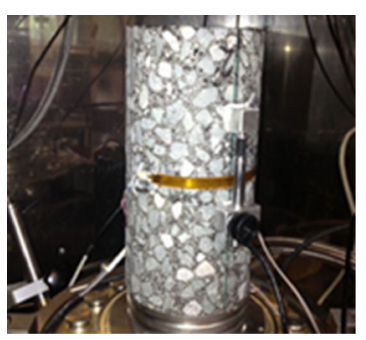

Front view

(e)

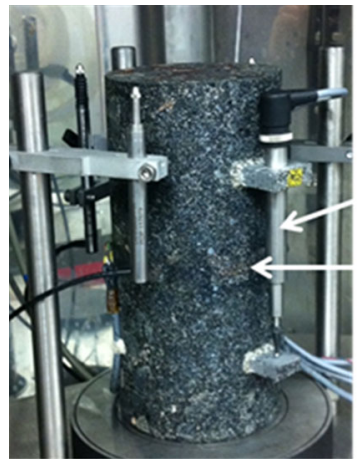

Front view

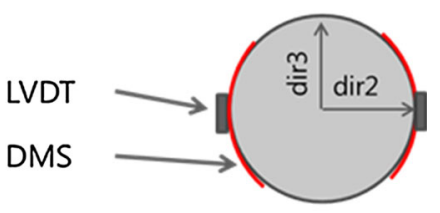

Top view

Fig. 4 Setup used by each laboratory involved in the RRT: a lab1; b lab2; c lab3; d lab4; e lab5

used for data acquisition. The sampling frequency $\left(f_{\mathrm{s}}\right)$ was adapted to the test frequency $\left(f_{\mathrm{t}}\right)$ to obtain 100 samples per cycle $\left(f_{\mathrm{s}}=100 f_{\mathrm{t}}\right)$.

The test program consisted of frequency sweeps $(12,4,1,0.25$ and $0.1 \mathrm{~Hz})$ carried out across five temperatures $\left(0,10,20,30\right.$ and $\left.40{ }^{\circ} \mathrm{C}\right)$. Tests were carried out in controlled stress mode. The stress level was adjusted for each test condition in order to obtain steady-state strain amplitude in the range of $40-50 \mu \mathrm{m} / \mathrm{m}$. For each test condition, 40 load cycles were applied.

The periodic component of each measured signal was extracted using a moving average filter and approximated using Fourier polynomials. The harmonic regression was carried out using the statistical software package R-project, using the algorithm 
described by Cowpertwait and Metcalfe [27]. The amplitudes and phase angles of the first harmonic component (fundamental harmonic) were used to calculate the complex Young's modulus and Poisson's ratio, according to Eqs. 4 and 5. Considering the position of the transverse strain gages only $v^{*}{ }_{2}$ (Eq. 5) and an averaged value of $v^{*}$ can also be obtained from the signals of the 3 transverse gages.

\subsubsection{Lab3}

Except for transversal strain measurements and the length of the extensometers used in direction 1 $(50 \mathrm{~mm})$, Lab3 used the same setup as Lab1. The maximum capacity of the hydraulic system used was $100 \mathrm{kN}$, with an axial displacement of $\pm 50 \mathrm{~mm}$. Circumferential strains were measured in direction 2 and direction 3 using 4 strain gages glued on the lateral surface of the core sample. Strain gages $50.8 \mathrm{~mm}$ in length and with a 120-Ohm resistance were used. Figure $4 \mathrm{c}$ shows the configuration of the instrumentation placed around the sample. For each transverse direction (dir2 and dir3), two strain gages were glued face to face on the cylinder wall and centered on the transversal axis, as shown in Fig. 4c. As wire connections were at one end of each strain gage, the total length of a strain gage could not allow all strain gages (4) to be placed at the same height around the sample core. As shown in the front view of Fig. 4c, one set of two strain gages $\left(\varepsilon_{3 a}\right.$ and $\left.\varepsilon_{3 b}\right)$ was placed face to face $45 \mathrm{~mm}$ from the top surface of the sample, and the other set at $70 \mathrm{~mm}\left(\varepsilon_{2 a}\right.$ and $\left.\varepsilon_{2 b}\right)$.

A quarter-bridge strain-gage configuration type $\mathrm{X}$ connection was used. To correct temperature effects two other strain gages were glued on a titanium silicate plate and subjected to the same test conditions as tested sample. The titanium silicate is characterized by an exceptionally low thermal contraction-expansion linear coefficient of $0.03 \times 10^{-6} \mu$ strain $/{ }^{\circ} \mathrm{K}$.

A thermal chamber was used to control the temperature of the specimen. The temperature was measured with a thermal gage (PT100 surface temperature probe) placed and held against the specimen surface with a rubber band. The glued cylindrical specimen $(74 \mathrm{~mm}$ in diameter and $123 \mathrm{~mm}$ in length) was loaded at 6 frequencies (from 0.03 to $10 \mathrm{~Hz}$ ) and 3 temperatures $(0,15$ and $30{ }^{\circ} \mathrm{C}$ ). The data acquisition time interval was adapted to have 100 points per cycle and signal analysis was conducted step by step by considering two consecutive cycles at a time. Experimental data related to the force and strains measured by the load cell, extensometers and strain gages were then fitted as sinusoidal functions. Amplitudes $\left(\sigma_{0}\right.$ and $\left.\varepsilon_{0 \mathrm{i}}\right)$ and phase angles $\left(\varphi_{\sigma}\right.$ and $\left.\varphi_{\varepsilon i}\right)$ were determined at each step using the least squares method. By calculating a quality index (QI) at each step of the analysis process, the accuracy of the approximated sinusoidal function as regard to data signal was checked. Data too far from sinusoidal signal were rejected. As defined in Sect. 3.3.1, the mean value of the three extensometers used for axial strain measurement was considered for $\varepsilon_{01}$ and $\varphi_{\varepsilon 1}$. In addition, radial strain in direction 2 and 3 are given by the average values from the two pairs of opposite gages (Eqs. 7 and 8)

$\varepsilon_{0 i}=\left(\varepsilon_{0 i a}+\varepsilon_{0 i b}\right) / 2 \quad(i=2,3)$

$\varphi_{\varepsilon i}=\left(\varphi_{\varepsilon i a}+\varphi_{\varepsilon i b}\right) / 2 \quad(i=2,3)$

\subsubsection{Lab4}

In lab4, the specimen was submitted to haversine compression loading using a servo hydraulic testing machine with a maximum capacity of $50 \mathrm{kN}$ and $a \pm 70 \mathrm{~mm}$ stroke. The nominal dimensions of the specimens were $100 \mathrm{~mm}$ diameter and $200 \mathrm{~mm}$ height. The axial displacement was measured on the middle part of the specimen $( \pm 20 \mathrm{~mm}$ from half height) by two LVDTs located $180^{\circ}$ around the specimen, with a nominal measuring range of $\pm 25 \mathrm{~mm}$. The radial strain was only measured in direction 2 by using two strain gages glued on the surface of the specimen around its circumference at mid height. The strain gages lengths were $100 \mathrm{~mm}$. Figure $4 d$ shows a specimen placed in the testing machine, with one axial LVDT, and one radial strain gage. The specimen was placed within a thermal chamber to control the temperature throughout the test. A second dummy specimen was placed in the chamber as well, with a thermal gage (PT 100) placed within a drilled hole of the specimen to record its core temperature.

In a series of pre-tests on another specimen of the same mix design, axial stress amplitudes were determined, with the strain amplitude around $50 \mu \mathrm{m} / \mathrm{m}$ for each test temperature and test frequency. Tests were run at $0,+15$ and $+30{ }^{\circ} \mathrm{C}$, and at frequencies ranging 
from 0.03 to $10 \mathrm{~Hz}$, with a total number of load cycles below 400 load cycles.

Data from the axial load cell was used to calculate axial stresses, the mean value of data from the two axial LVDTs allows calculating axial strain, and the mean value of data from the two radial strain gages gives the radial strain in direction 2 . These data were fitted with sinusoidal functions. For optimization stability, data fitting was carried out for subsequent packages of 3 load cycles.

\subsubsection{Lab5}

Force control cyclic compression tests were used with no lateral pressure using a servo hydraulic testing machine with a maximum loading capacity of $25 \mathrm{kN}$ and $a \pm 50 \mathrm{~mm}$ stroke. The nominal dimensions of the cylindrical specimens were $100 \mathrm{~mm}$ diameter and $200 \mathrm{~mm}$ height. For the cyclic compression test, upper and lower stress amplitudes were defined using precalibration tests. In a force control test, it is very difficult to keep the strain amplitude constant as in the experiments of lab1, 2 and 3. However the stress amplitudes were chosen so that the resulting strain amplitude remains below $\pm 50 \mu \mathrm{m} / \mathrm{m}$. Before the experiments, the specimens were conditioned at the test temperature $(T)$ for at least four hours. The temperature was measured on the surface of the specimen,inside the specimen at $1 / 4$ height from bottom, and on a dummy specimen that was not tested, but that was located at the same level in the chamber as the tested specimen. Very little variation in temperature was noted, indicating that the temperature inside the specimen did not significantly change during the experiments, and that the temperature was homogeneous within the specimen $\left(<0.3{ }^{\circ} \mathrm{C}\right.$ difference). The strains in direction 1 were measured using two LVDTs and in direction 3 using two $50 \mathrm{~mm}$ strain gages (DMS1 and DMS2) facing each other, as shown in Fig. 4e. The test program included six frequencies from 0.03 to $10 \mathrm{~Hz}$ and temperatures of 0,15 and $30{ }^{\circ} \mathrm{C}$. For each test condition between 10 and 200 loading cycles were applied. The axial stress $\left(\sigma_{1}\right)$ was obtained from the load cell signal and radial strains $\left(\varepsilon_{3}\right)$ were calculated from the two pairs of strain gages. Sinusoidal curves of strain and stress were fitted to the experimental data $\left(\varepsilon_{1}, \sigma_{1}\right.$, and $\left.\varepsilon_{3}\right)$ and used to calculate the norm and phase angle of the complex Young's modulus $\left(E^{*}\right)$ and complex Poisson's ratios $\left(v_{3}^{*}\right)$ using
Eqs. 1-6. The resulting values were the average of the two measurements both in the axial direction and radial direction.

Table 2 gives an overview of the testing conditions applied by each laboratory during the RRT program.

\section{Experimental results, analysis and comparison}

The presentation and analysis of round robin results are performed in two steps. First, in order to provide overall trends and reproducibility of the measured complex Young's modulus and complex Poisson's ratios, unprocessed results are compared. In a second step, an analysis based on simulations using the 2S2P1D model in 3 dimensions [28] is proposed. As small differences in testing conditions do exist between the laboratories, any direct comparison may bring non-realistic conclusions. To overcome this drawback, the 2S2P1D model is used to quantify the differences between the laboratories.

\subsection{Measured complex Young's modulus $\left(E^{*}\right)$ and complex Poisson's ratios $\left(v^{*}\right)$}

\subsubsection{Black diagrams and Cole-Cole plots}

Experimental results for complex moduli and complex Poisson's ratios from the 5 laboratories are plotted in Fig. 5 in Black diagrams and Col-Cole plots. The advantage of these types of plots is that data comparison is not affected by eventual errors due to temperature appreciation for thermorhelogically simple materials [i.e. which respect the time-temperature superposition principle (TTSP)]. Two samples were tested by lab1 (lab1_sp1 and lab1_sp2) and one sample by other laboratories. In this Figure, the complex Young's modulus and complex Poisson's ratio results, obtained from measurements of all laboratories, appear rather close for all plots. The complex Young's modulus values reveal more scattering in both types of axes.

As can be seen in Fig. 5, complex Poisson's ratios values are a function of both temperature and frequency. In addition all data are situated along a unique curve on each Figure, which show that TTSP is respected for this parameter. Except for test results involving highest temperatures, the complex Poisson's ratio phase angle values are negative, signifying 


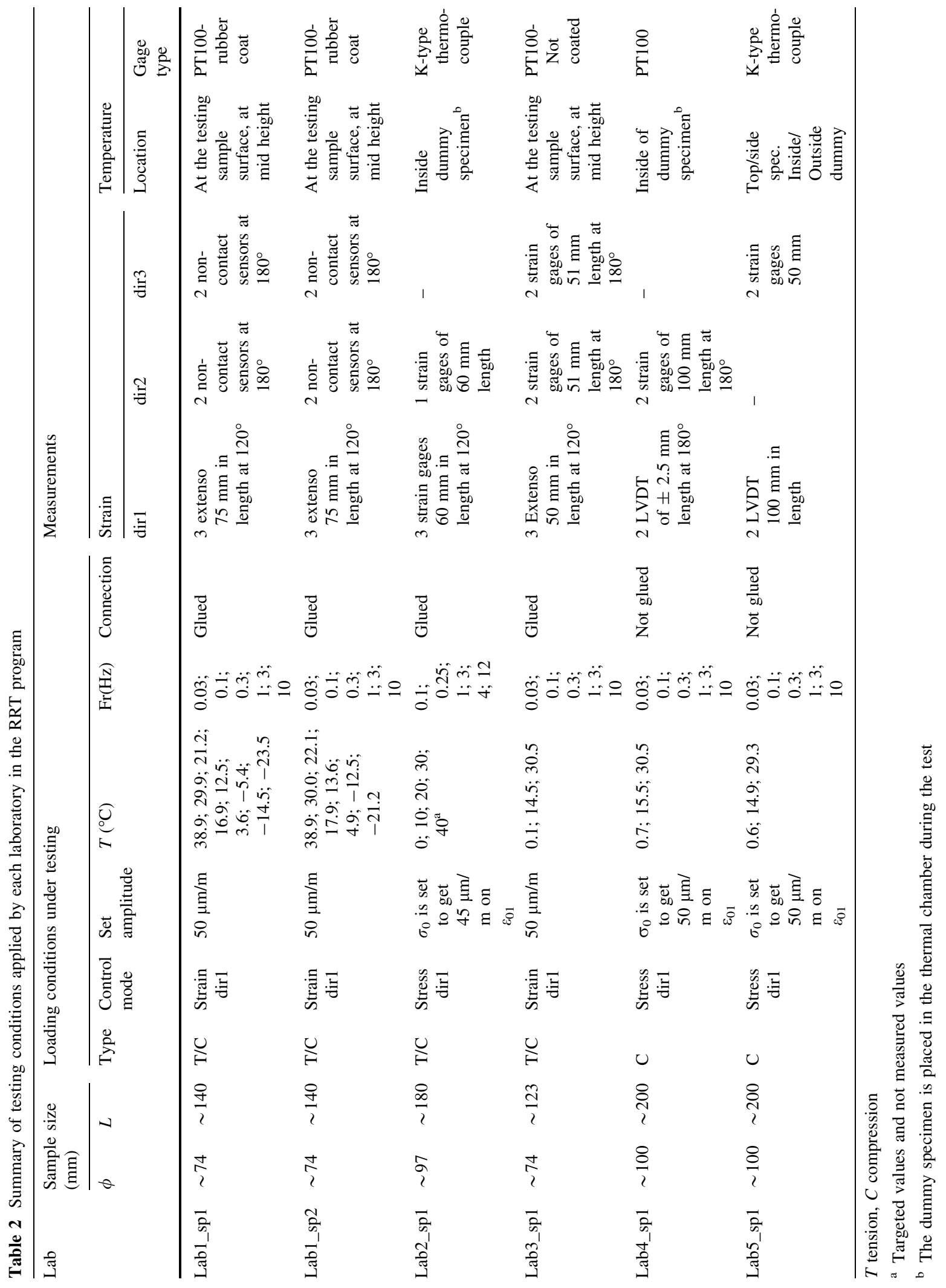


Fig. 5 Experimental results (data points) and 2S2P1D simulation curves: a complex modulus in Black diagram; b complex modulus in Cole-Cole plot; c complex Poisson's ratio in $\operatorname{dir} 2\left(v_{2}\right)$ in Black diagram; d complex Poisson's ratio in $\operatorname{dir} 2\left(v_{2}\right)$ in Cole-Cole plot; e complex Poisson's ratio in $\operatorname{dir} 3\left(v_{3}\right)$ in Black diagram; f complex Poisson's ratio in $\operatorname{dir} 3\left(v_{3}\right)$ in Cole-Cole plot
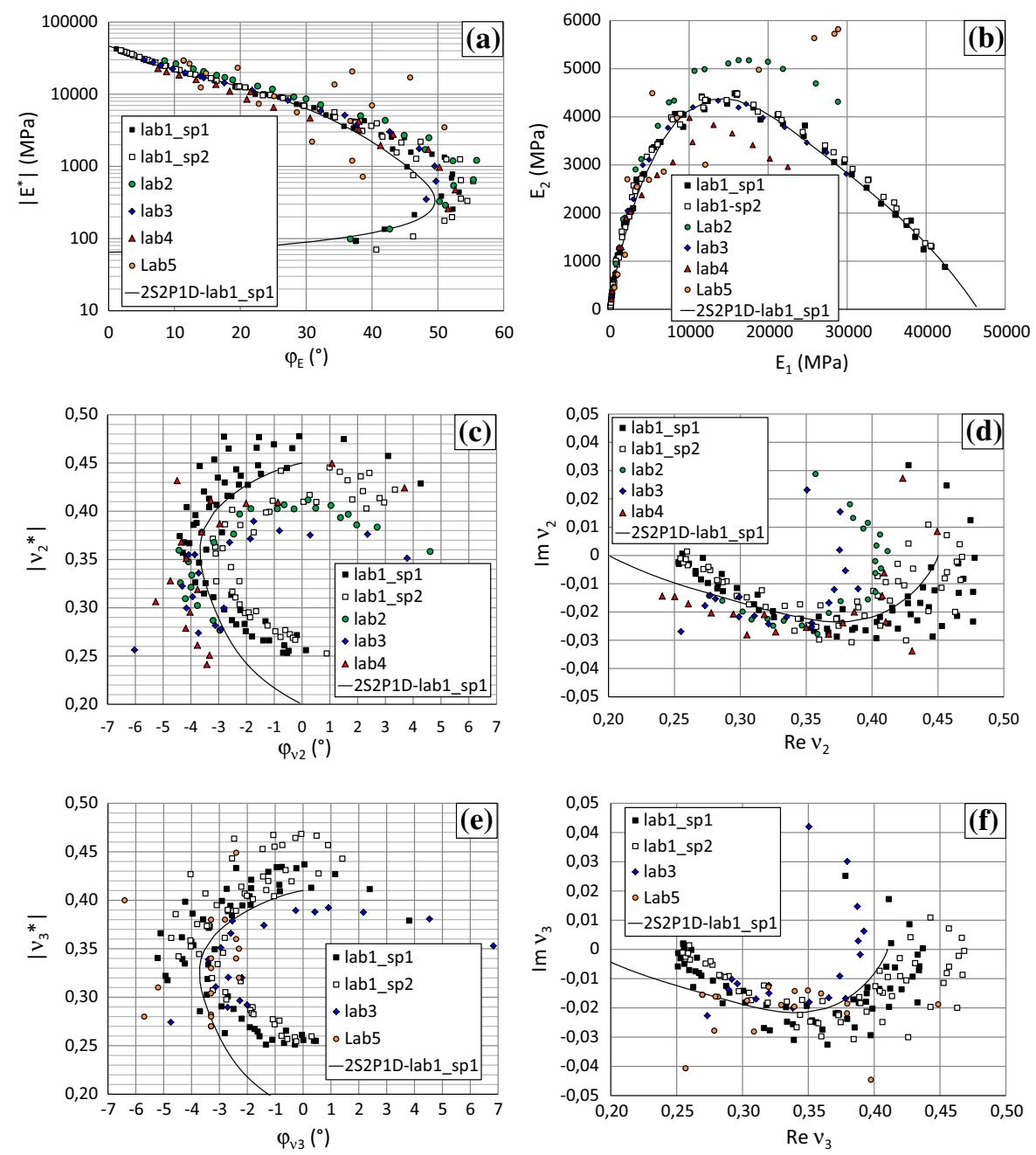

that the opposite radial strain lags behind the axial strain.

The complex Poisson's ratio values presented in Fig. 5 are between 0.25 and 0.48 , which is a significant range for this parameter. Viscous and thermo-susceptibility effects are then of utmost importance and should not be ignored. From both the Black diagrams and the Cole-Cole plots it can be observed that the scattering of the complex Poisson's ratio is smaller at low temperatures and/or high frequencies, i.e. the norm falls in the range $0.25-0.27$, and the phase angle gets close to 0 (see also Fig. 8). On the other hand, at high temperatures and/or low frequencies higher dispersion appears (values between 0.35 and 0.48), whereas the phase angle progressively becomes positive (Fig. 8). It is emphasized that results appear less dispersed when the norm values are lower, even though in such conditions the smaller transverse strain values should bring higher measurement noise in the results.

Furthermore, the Poisson's ratio values of lab2 and lab3 are closer for direction 2 (Fig. 5c-f), and often seem to be slightly lower than the one measured by lab1. One contributing factor could be that the strain gages glued around the sample may restrain transversal deformation. Based on the testing program, this question could not be properly answered.

The difference in Poisson's ratios in both directions, that allows to check whether the tested material is isotropic regarding transversal deformation, can only be obtained from lab1 and lab3 data. Figure 6 shows the relationship between the norm of the complex Poisson's ratio values in direction $2\left(\left|v_{2}\right|\right)$ and the norm values in direction $3\left(\left|v_{3}\right|\right)$ from 3 tests. 
Results from lab1 are mainly above the equality line, while those from lab3 are somewhat below. The maximum absolute difference in the norms of the complex Poisson's ratios to the equality line is less than 0.05. As the magnitude of the applied axial strain amplitude was close to $50 \mu \mathrm{m} / \mathrm{m}, 0.05$ difference in Poisson's ratio values corresponds to a difference of about $0.19 \mu \mathrm{m}$ in diameter amplitude variation for the tested sample. Consequently, it can be considered that the difference is quite small and situated within the accuracy range of the experimental procedure. Then, the authors believe that this small difference is related to measurement accuracy. From our results, it is not possible to conclude about the anisotropic behaviour of the material. Meanwhile, if the behaviour is anisotropic, the anisotropy doesn't create a difference between Poisson's ratio values in direction 2 and 3 .

\subsubsection{Master curves of complex Young's modulus and complex Poisson's ratios}

Master curves of complex Young's modulus and complex Poisson's ratios can be used when TTSP is respected. Then only one variable, the equivalent frequency $\left(\mathrm{fr}_{\mathrm{eq}}\right.$ ) takes into account the effect of both temperature and frequency. Equivalent frequency is the product of shift factor $a_{\text {Tref }}(T)$, which depends only on the temperature $(T)$ and the chosen reference temperature ( $\left.T_{\text {ref }}\right)$, by frequency (Eq. 9)

$\mathrm{fr}_{\mathrm{eq}}=a_{T} \times \mathrm{fr}$

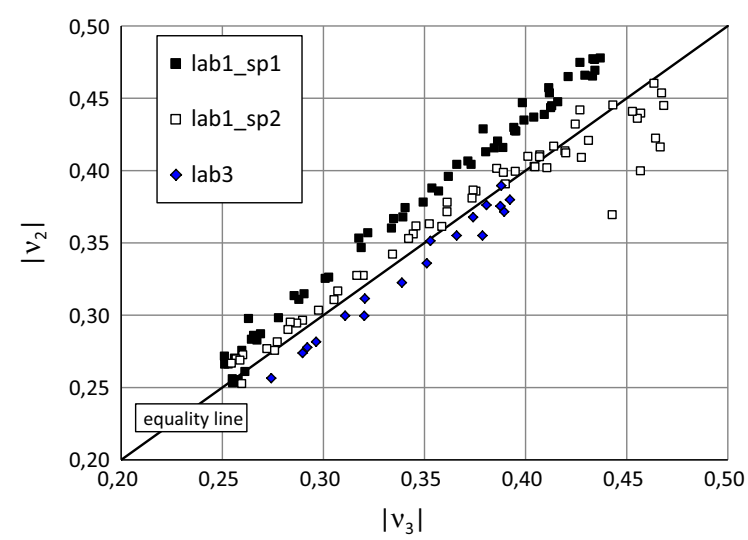

Fig. 6 Norm of the complex Poisson's ratio in direction $2\left(\left|v_{2}\right|\right)$ and the norm of the complex Poisson's ratio in direction $3\left(\left|v_{3}\right|\right)$
Master curves obtained from the results of the different laboratories were considered at a reference temperature of $0{ }^{\circ} \mathrm{C}$.

Figure 7 shows the values of obtained experimental shift factors $\left(a_{\mathrm{TE}}\right)$ as a function of temperatures established for each laboratory. The results from each laboratory follow the same trend and are relatively close.

It should be underlined that shift factor values for complex Poisson's ratios (directions 2 and 3) and complex Young's modulus are the same. This confirms the results presented by [3, 28-32], who already showed the validity of TTSP for Poisson's ratio measurements. They also showed that shift factors used to build the Poisson's ratio master curve are very close to those $\left(\mathrm{a}_{\mathrm{TE}}\right)$ obtained for the complex modulus, that can be considered as identical values.

Figure 8 shows the master curves of the complex Young's modulus and complex Poisson's ratios obtained for each laboratory involved in the round robin program. The norm of the complex modulus increases as a function of frequency and, inversely, it decreases as a function of temperature, which was expected. It's phase angle $\varphi_{\mathrm{E}}$ increases as a function of frequency up to a given maximum, and then decreases.

Differences were observed in the complex modulus master curves between the laboratories. Contrary to what was observed in Fig. 5, the complex modulus master curves of lab3 show a clear difference with those of lab1. As Fig. 5 shows close results for lab1 and lab3, the observed differences in the master curves

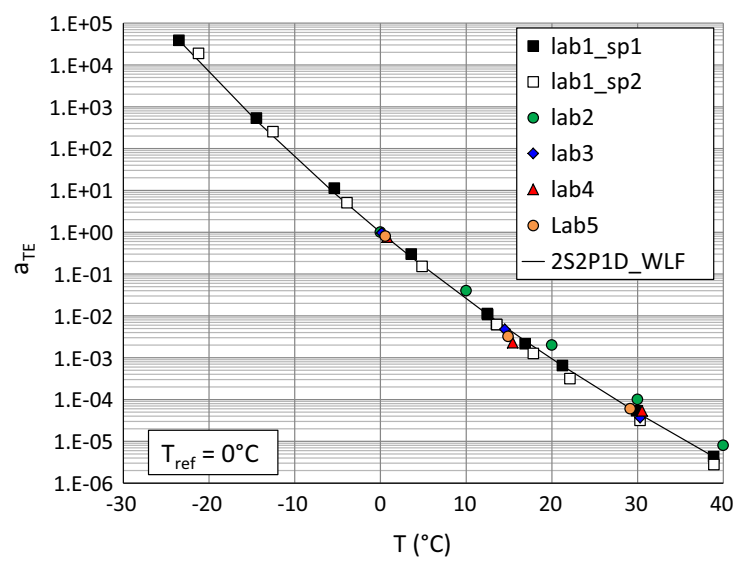

Fig. 7 Shift factors $a_{\mathrm{TE}}$, for all tested samples; same values are obtained for complex Young's and Poisson's ratios 
can be attributed to temperature measurement error between the two laboratories. This point is confirmed because a shift along the equivalent frequency axis makes the curves from the 2 laboratories identical. The shift value is 0.31 , which, from Fig. 7 , gives a temperature error of $3{ }^{\circ} \mathrm{C}$ between the 2 laboratories.

The techniques used to measure the testing temperature at the sample surface could mainly explain the gap. Lab1 used a PT100 rubber coated temperature probe put on the sample surface and held in place with a rubber band. In contrast, lab3 used a PT100 uncoated temperature probe, also placed on the sample surface and held in place with a rubber band. The utmost importance of a correct temperature conditioning and measurement is then again to be stressed.
4.2 Simulation and comparison using the 2S2P1D model

\subsubsection{Presentation of 2S2P1D model and calibration from results of test Lab1_sp1}

As measurements from each laboratory are not performed at exactly the same temperatures and same frequencies, it is not possible to compare the data directly. It was decided by the group to compare all data to a common reference given by the 2S2P1D (2 Springs, 2 Parabolic creep elements and 1 Dashpot in one dimension) linear viscoelastic model. The calculated 2S2P1D values can be obtained for any experimental frequency and temperature condition and compared with experimental data.
Fig. 8 Master curves of tested samples (data points) and 2S2P1D simulation curves (solid lines): a norms of the complex modulus; b phase angles of complex modulus; c norms of complex Poisson's ratio of $v_{2} ; \mathbf{d}$ phase angles of complex Poisson's ratio of $v_{2}$; e norms of complex Poisson's ratio of $v_{3}$; $\mathbf{f}$ phase angles of complex Poisson's ratio of $v_{3}$
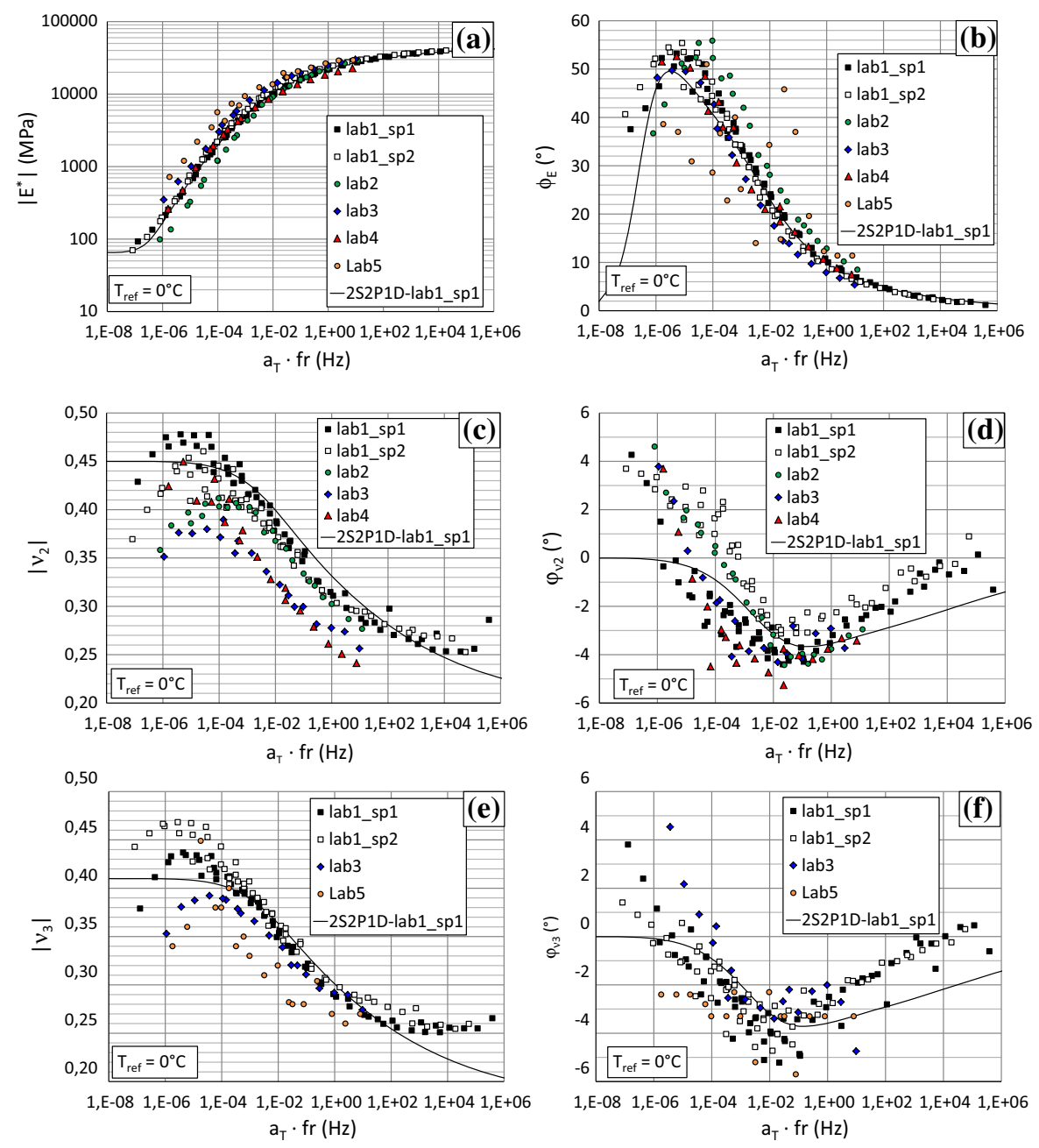
The 2S2P1D model, developed at the University of Lyon/ENTPE, is a generalization of the Huet-Sayegh model. The 2S2P1D model is based on a simple combination of physical elements (spring, dashpot and parabolic elements). The graphical representation of the 2S2P1D model is given in Fig. 9. It is widely used to model the linear viscoelastic unidimensional or tridimensional behavior of bituminous materials (including binders, mastics and mixes) [33-38].

The 2S2P1D analytical expression of complex Young's modulus and the Poisson's ratio, at a specific temperature, is given by Eqs. 10 and 11 .

$$
\begin{aligned}
& E_{2 \mathrm{~S} 2 \mathrm{P} 1 \mathrm{D}}^{*}(\omega) \\
& \quad=E_{00}+\frac{E_{0}-E_{00}}{1+\delta\left(\mathrm{j} \omega \tau_{E}\right)^{-k}+\left(\mathrm{j} \omega \tau_{E}\right)^{-h}+\left(\mathrm{j} \omega \beta \tau_{E}\right)^{-1}}
\end{aligned}
$$

$$
\begin{aligned}
& v_{i / 2 \mathrm{~S} 2 \mathrm{P} 1 \mathrm{D}}^{*}(\omega) \\
& =v_{i 00}+\frac{v_{i 0}-v_{i 00}}{1+\delta\left(j \omega \tau_{v}\right)^{-k}+\left(j \omega \tau_{v}\right)^{-h}+\left(j \omega \beta \tau_{v}\right)^{-1}}
\end{aligned}
$$

where: $\mathrm{j}$ is the complex number defined by $\mathrm{j}^{2}=-1, \omega$ is the angular frequency, $\omega=2 \pi f$, ( $f$ is the frequency), $k, h$ are the constant exponents such that $0<k<h<1, \delta$ is the constant, $E_{00}$ the static modulus when $\omega \rightarrow 0, E_{0}$ the glassy modulus when $\omega \rightarrow \infty, v_{i 00}$, the static Poisson's ratio in direction " $i$ " when $\omega \rightarrow 0$ (for $i=2$ and 3), $v_{i 0}$ is the glassy Poisson's ratio in direction " $i$ " when $\omega \rightarrow \infty$ (for

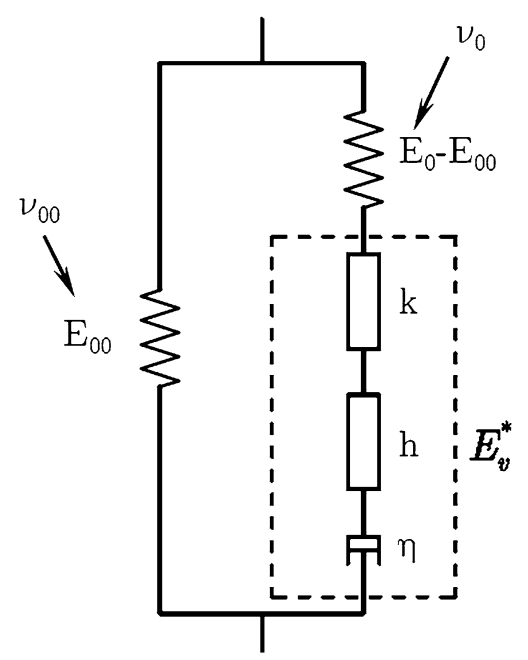

Fig. 9 Analogical representation of the 2S2P1D model [28, 37] $i=2$ and 3), $\beta$ is the parameter linked with $\eta$, the Newtonian viscosity of the dashpot, $\eta=\left(E_{0}-E_{00}\right)$ $\beta \tau_{E}, \tau_{E}$ and $\tau_{v}$ are the characteristic time values, which are only parameters depending on temperature and have a similar evolution:

$\tau_{E}(T)=a_{T}(T) \cdot \tau_{0 E} \quad$ and $\quad \tau_{v}(T)=a_{T}(T) \cdot \tau_{0 v}$

where $a_{T \mathrm{ref}}(T)$ is the shift factor at temperature $T$, $\tau_{E}=\tau_{0 E}$ and $\tau_{v}=\tau_{0 v}$ at reference temperature $T_{\text {ref. }}$. Ten constants $\left(E_{00}, E_{0}, \delta, k, h, \beta, v_{\mathrm{i} 00}, v_{\mathrm{i} 0}, \tau_{0 \mathrm{E}}, \tau_{0 \mathrm{v}}\right)$ are required to completely characterize the $3 \mathrm{D} \mathrm{LVE}$ properties (with isotropy hypothesis) of the tested material at a given temperature. The evolutions of $\tau_{\mathrm{E}}$ and $\tau_{v}$ were approximated by the WLF equation [39] (Eq. 13). $\tau_{0 \mathrm{E}}$ and $\tau_{0 v}$ were determined at the chosen reference temperature $T_{\text {ref }}=0{ }^{\circ} \mathrm{C}$. When the temperature effect is considered, the number of constants becomes twelve, including the two WLF constants $\left(C_{1}\right.$ and $C_{2}$ calculated at the reference temperature).

$\log \left(a_{T}\right)=-\frac{C_{1}\left(T-T_{\text {ref }}\right)}{C_{2}+T-T_{\text {ref }}}$

2S2P1D constants were fitted using results from lab1_sp1 sample. The 2S2P1D and WLF constants are reported in Table 3. Simulation curves obtained from 2S2P1D model are also plotted in Figs. 5, 7 and 8 together with experimental data points.

\subsubsection{Difference between experimental results and $2 S 2 P 1 D$ simulated values}

The relative differences between the calibrated WLF values, using constants of Table 3 , and the corresponding experimental data for shift factor $\left(\mathrm{a}_{\mathrm{T}}\right)$ are presented in Fig. 10. What should be observed to characterize reproducibility of the test is the difference between the different data points and not the obtained relative difference values. These last values give information on quality of the simulation for each test condition. If results from lab2 are not considered, the differences between values for other specimens are within a range of $\pm 25 \%$ on the whole frequency and temperature range. This value is quite small when comparing to the range of variation of the shift factor parameter, which covers more than 10 decades [from $3 \times 10^{-6}$ to $4 \times 10^{+4}$ (Fig. 7)]. Larger differences observed for the specimen from Lab2 up to $150 \%$ are obtained at higher temperatures. 
Table 3 2S2P1D parameters and WLF constants set at $0{ }^{\circ} \mathrm{C}$ in accordance with data of lab1_sp1 tested sample

\begin{tabular}{|c|c|c|c|c|c|c|c|c|c|c|c|c|c|c|}
\hline \multicolumn{12}{|c|}{ 2S2P1D parameters } & \multicolumn{3}{|c|}{ WLF constants } \\
\hline$E_{00}(\mathrm{MPa})$ & $E_{0}(\mathrm{MPa})$ & $k$ & $h$ & $\delta$ & $\tau_{\mathrm{OE}}(\mathrm{s})$ & $\beta$ & $v_{200}$ & $v_{20}$ & $v_{300}$ & $v_{30}$ & $\tau_{0 v}(\mathrm{~s})$ & $C_{1}$ & $C_{2}$ & $T_{\text {ref }}\left({ }^{\circ} \mathrm{C}\right)$ \\
\hline 65 & 46600 & 0.150 & 0.500 & 1.540 & 4.58 & 180 & 0.45 & 0.20 & 0.41 & 0.18 & 4.58 & 29.45 & 174.40 & 0 \\
\hline
\end{tabular}

The complex moduli and complex Poisson's ratios are calculated with the 2S2P1D model considering exact temperature and frequency values for each data condition. Obtained values are noted with subscript "2S2P1D lab1_sp1" indicating that the calibration was

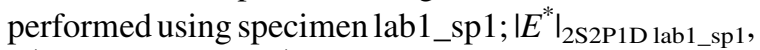

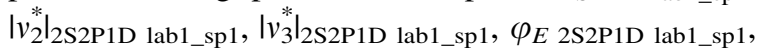
$\varphi_{v 2}$ 2S2P1D lab1_sp1 and $\varphi_{v 3}$ 2S2P1D lab1_sp1. Figure 11 shows the relative differences between simulated and experimental values for complex modulus absolute (norm) values (Fig. 11a) and differences between simulated and experimental values for the 5 other parameters (Fig. 11b-f).

A first glance on Fig. 11 shows that, for all equivalent frequencies, points having the lowest difference values are from test lab1_sp1. This result was expected as the calibration of the model is made from the data of this test. The rather low difference values for this specimen indicate that $2 \mathrm{~S} 2 \mathrm{P} 1 \mathrm{D}$ is able to simulate correctly the observed behavior on the whole range of temperatures and frequencies. For all 6 parameters, simulation results are better for low temperature and/or high frequencies.

Comparison between results from the different tests should consider the thickness of the clouds of points

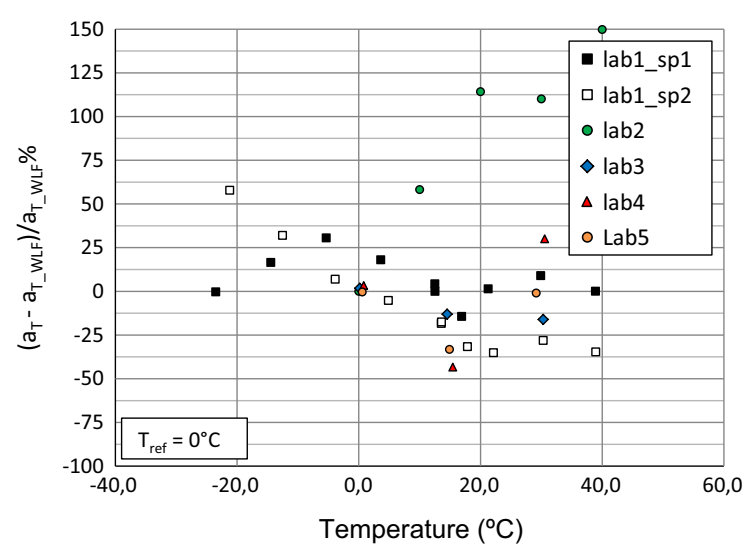

Fig. 10 Relative differences between experimental results and simulated values using WLF equation calibrated with test Lab1_sp1 (i.e. the range of variation) and not its position on the $y$ axis. Figure 11a shows that the scattering of the relative difference in the values of modulus increases for low values of reduced frequencies $\left(a_{T} \cdot \mathrm{fr}\right)$ and reach an overall difference of $250 \%$ (between +200 and $-50 \%$ at $a_{T} \cdot \mathrm{fr}=10^{-6}$ ). Complex Young's modulus values of lab3 and lab5 have the maximum deviation. This large difference can be explained for lab3 by an error in sample temperature measurements, as explained further (see Fig. 12). Figure 11c, e show that differences in the norms of the complex Poisson's ratios are smaller than about \pm 0.05 . As already noted in Sect. 4.1.1, this value is in the range of the accuracy limit of measurement systems and should be considered as good reproducibility.

It was noted previously that lab3 may have recorded incorrect temperature measurements. In Sect. 4.1.2, it is estimated that the temperature error is about $3{ }^{\circ} \mathrm{C}$. 2S2P1D values for lab3 were then recalculated considering a shift in temperature of $-3{ }^{\circ} \mathrm{C}$ and $-2{ }^{\circ} \mathrm{C}$. Differences between experimental values of lab3 and 2S2P1D values, calculated at $-3{ }^{\circ} \mathrm{C}$ and $-2{ }^{\circ} \mathrm{C}$, are plotted in Fig. 12. Previous difference values for lab1 (determined at $0{ }^{\circ} \mathrm{C}$ ) are also plotted in Fig. 12. As compared with results of Fig. 11 scattering of results are considerably reduced, which confirms the probable error of 2 to $3{ }^{\circ} \mathrm{C}$ in temperature measurement between the two laboratories, confirming the importance of accurate temperature measurements.

\section{Conclusions}

In this paper, the results of five laboratories involved in a Round Robin Test (RRT) on complex Poisson's ratio measurements were analyzed. The material tested by all laboratories was a standard base course bituminous mixture commonly used in France (GB3). Axial and transversal strain were measured under sinusoidal lading applied to the specimen along direction 1 (axial direction), using different methods in five laboratories. Two of the five laboratories 
Fig. 11 Difference between experimental results and simulated values from 2S2P1D model calibrated with test Lab1_sp1: a norms of the complex modulus; b phase angles of the complex modulus; $\mathbf{c}$ norms of the complex Poisson's ratio in $\operatorname{dir} 2\left(v_{2}\right)$; d phase angles of the complex Poisson's ratio in $\operatorname{dir} 2\left(v_{2}\right)$; e norms of the complex Poisson's ratio in $\operatorname{dir} 3\left(v_{3}\right)$; $\mathbf{f}$ phase angles of the complex Poisson's ratio in $\operatorname{dir} 3\left(v_{3}\right)$
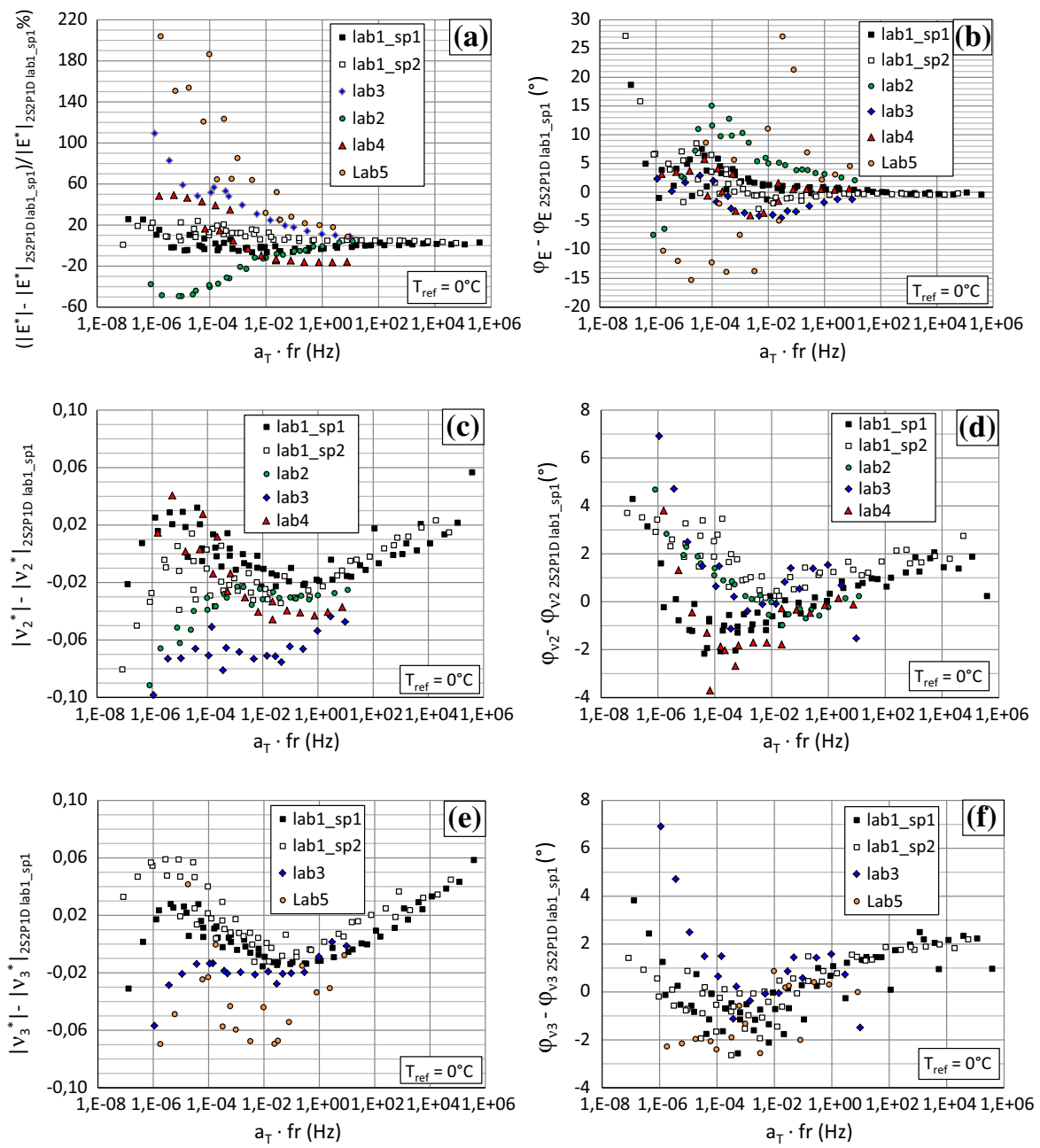
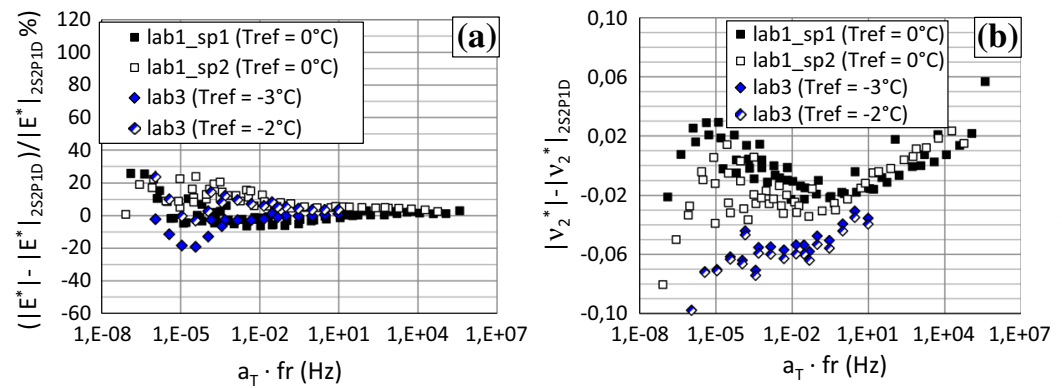

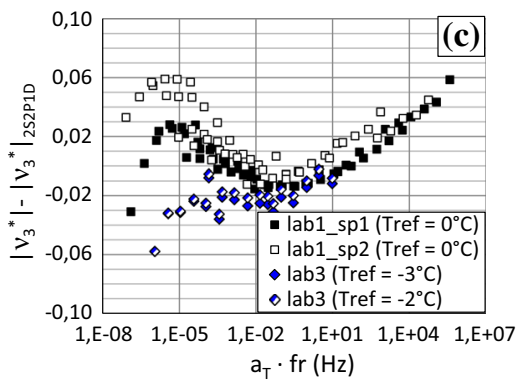

Fig. 12 Differences between experimental values of lab3 and 2S2P1D lab1_sp1 values calculated at $T_{\text {ref }}=-3{ }^{\circ} \mathrm{C}$ and $T_{\text {ref }}=-2{ }^{\circ} \mathrm{C}$ against reduced frequencies $\left(a_{\mathrm{T}} \cdot \mathrm{fr}\right)$ : a norms of

involved in the RRT carried out measurements of the transversal strain of the core sample in two orthogonal directions (dir2 and dir3) while the others conducted the complex modulus; b norms of the complex Poisson's ratio in $\operatorname{dir} 2\left(v_{2}\right)$; $\mathbf{c}$ norms of the complex Poisson's ratio in $\operatorname{dir} 3\left(v_{3}\right)$

measurements in one direction only. The complex Young's modulus and complex Poisson's ratios are reported in this paper as calculated in reference to 
equations detailed in Sect. 2. All the laboratories tested one cored sample (sp1) and lab1 carried out a replicate sample test ( $\mathrm{sp} 2)$.

Based on the results, it can be concluded that:

1. Complex Young's modulus and complex Poisson's ratios obtained from all laboratories are very close in Black diagrams, but diverge sharply in the Cole-Cole plot of the complex Young's modulus.

2. The maximum absolute difference between the complex Poisson's ratio in direction 2 and the one in direction 3 is less than 0.05 . The disparity is more related to measurement accuracy than to the anisotropy of the material.

3. The relationship between the shift factors and the temperatures established for each laboratory are close and follow the same trend.

4. Some differences were observed in the master curves of complex Young's modulus and complex Poisson's ratios obtained from each laboratory. In some cases, the observed differences on the master curves could be attributed to temperature differences.

5. Based on the 2S2P1D model calibrated on lab1_sp1 data, the difference between 2S2P1D values, established in accordance with the specific conditions of each laboratory and experimental results were analyzed, and show that:

(a) The relative scattering of different complex Young's modulus values increases for low reduced frequencies (high temperatures) and reach an overall difference of $250 \%$; However, this difference vanishes for high relative frequencies (low temperatures).

(b) The relative differences in the norms of complex Poisson's ratios are much lower than were noted for norms of complex Young's modulus, with a maximum deviation of $30 \%$.

In summary, it can be concluded that the small strain domain measurements performed in each laboratory show a typical and similar rheological behavior for the material tested, and the material response typically follows the same trend between the laboratories with respect to the temperature.

Acknowledgments The authors thank the members of the RILEM Technical Committee 237-SIB TG3 who worked for the inter-laboratory tests program. The laboratories and their technical and scientific staff, which participated in the test program, are gratefully thanked for their large and efficient contribution.

\section{References}

1. Blanc J, Gabet T, Hornich P, Piau JM, Di Benedetto H (2015) Cyclic triaxial tests on bituminous mixtures. Road Mater Pavement Des 16(1):46-69. doi:10.1080/14680629. 2014.964293

2. Bocci E, Graziani A, Canestrari F (2015) Mechanical 3D characterization of epoxy asphalt concrete for pavement layers of orthotropic steel decks. Constr Build Mater 79:145-152

3. Di Benedetto H, Mondher N, Sauzeat C, Olard F (2007) Three-dimensional thermo-viscoplastic behaviour of bituminous materials - the DBN model. Road Mater Pavement Des 8(2):285-315. doi:10.3166/RMPD.8.285-315

4. Di Benedetto H, Sauzeat C, Sohm J (2009) Stiffness of bituminous mixtures using ultrasonic wave propagation. Road Mater Pavement Des 10(4):789-814. doi:10.3166/ RMPD.10.789-814

5. Graziani A, Bocci M, Canestrari F (2014) Complex Poisson's ratio of bituminous mixtures: measurement and modeling. Mater Struct 47(7):1131-1148

6. Graziani A, Bocci E, Canestrari F (2014) Bulk and shear characterization of bituminous mixtures in the linear viscoelastic domain. Mech Time-Depend Mater 18(3):527-554. doi:10.1007/s11043-014-9240-x

7. Gudmarsson A, Ryden N, Di Benedetto H, Sauzeat C, Tapsoba N, Birgisson B (2014) Comparing linear viscoelastic properties of asphalt concrete measured by laboratory seismic and tension-compression tests. J Non Destr Eval 33(4):571-582

8. Hofko B (2012) Hot mix asphalt under cyclic compressive loading. Suedwestdeutscher Verlag fuer Hochschulschriften, Saarbrücken ISBN: 978-3-8381-3298

9. Mounier D, Di Benedetto H, Sauzeat C (2012) Determination of bituminous mixtures linear properties using ultrasonic wave propagation. Constr Build Mater 36:638-647. doi:10.1016/j.conbuildmat.2012.04.136

10. Nguyen HM, Pouget S, Di Benedetto H, Sauzeat C (2009) Time-temperature superposition principle for bituminous mixtures. Eur J Environ Civ Eng 13(9):1095-1107. doi:10. 3166/EJECE.13

11. Pouget S, Sauzeat C, Di Benedetto H, Olard F (2010) From the behavior of constituent materials to the calculation and design of orthotropic bridge structures [Special Issue: EATA 2010]. Road Mater Pavement Des 11:111-144. doi:10.3166/RMPD.11HS

12. Pouget S, Di Benedetto H, Sauzeat C, Olard F (2012) Effect of Vehicle Speed on the Millau Viaduct Response. J Test Eval 40:7

13. Pouget S, Sauzeat C, Di Benedetto H, Olard F (2012) Modeling of viscous bituminous wearing course materials on orthotropic steel deck. Mater Struct 45(7):1115-1125. doi:10.1617/s11527-011-9820-z

14. Maher A, Bennert T (2008) Evaluationh of Poissons's ratio for use in the mechanistic empirical pavament design guide 
(MEPDG), Report submit to Federal Highway Administration U.S., Department of transportation, Washington, D.C., \#FHWA-NJ-2008-004

15. Schwartz CW, Li R, Ceylan H, Kim S, Gopalakrishnan K (2013) Global sensitivity analysis of mechanistic-empirical performance predictions for flexible pavements. In: Transportation Research Board (TRB) 92nd annual meeting, Washington, DC, 13-17 Jan 2013

16. Hofko B, Blab R (2014) Enhancing triaxial cyclic compression testing of hot mix asphalt by introducing cyclic confining pressure. Road Mater Pavement Des 15(1):16-34. doi:10.1080/14680629.2013.844197

17. Airey G, Rahimzadeh B, Collop A (2003) Viscoelastic linearity limits for bituminous materials. In: 6th international RILEM symposium on performance testing and evaluation of bituminous materials, Zurich, pp 331-338

18. Di Benedetto H, Partl MN, Francken L et al (2001) Stiffness testing for bituminous mixtures. Mater Struct 34(236):66-70

19. Nguyen QT, Di Benedetto H, Sauzéat C (2015) Linear and nonlinear viscoelastic behaviour of bituminous mixtures. Mater Struct [doi: 10.1617/s11527-014-0316-5], on line first, May 2014

20. Tschoegl NW (1989) The phenomenological theory of linear viscoelastic behavior: an introduction. Springer, Berlin

21. NF EN 12697-33 + A1 (2007) Mélange bitumineuxMéthodes d'essai pour mélange hydrocarboné à chaudPartie 33: confection d'éprouvettes au compacteur de plaque, European Standard - French Standard AFNOR

22. NF EN 12697-35 + A1 (2007) Mélanges bitumineuxMéthodes d'essai pour mélange hydrocarboné à chaudPartie 35: malaxage en laboratoire, European Standard French Standard AFNOR

23. Di Benedetto H, Nguyen QT, Sauzeat C (2011) Nonlinearity, heating, fatigue and thioxotropy during cyclic loading of asphalt mixtures. Road Mater Pavement Des 12(1):129-158

24. Nguyen QT, Di Benedetto H, Sauzéat C (2012) Determination of thermal properties of asphalt mixtures as another output from cyclic tension-compression test. Road Mater Pavement Des 13(1):85-103. doi:10.1080/14680629.2011. 64408

25. Pham NH, Sauzéat C, Di Benedetto H, Gonzalez-Leon JA, Barreto G, Nocolai A, Jajubowski M (2015) RAP and additive influence on 3D linear behaviour of warm bituminous mixtures. Road Mater Pavement Des [doi:10.1080/ 14680629.2015.1021108], on line first, March 2013

26. Pham NH, Sauzéat C, Di Benedetto H, Gonzalez-Leon JA, Barreto G, Nocolai A, Jajubowski M (2015) Analysis and modeling of $3 \mathrm{D}$ complex modulus tests on hot and warm bituminous mixtures. Mech Time Depend Mater [doi:10. 1007/s11043-015-9258-8], on line first, March 2015
27. Cowpertwait PS, Metcalfe AV (2009) Introductory time series with R. Springer, Berlin

28. Di Benedetto H, Delaporte B, Sauzeat C (2007) Three dimensional linear behavior of bituminous materials: experiments and modeling. Int J Geomech 7:149-157. doi:10.1061/(ASCE)1532-3641(2007)7:2(149

29. Clec'h P, Sauzéat C, Di Benedetto H (2010) Linear viscoelastic behavior and anisotropy of bituminous mixture compacted with a French wheel compactor.In: 2nd international GeoShanghai conference

30. Nguyen ML, Sauzéat C, Di Benedetto H, Tapsoba N (2013) Validation of the time-temperature superposition principle for crack propagation in bituminous mixtures. Mater Struct 46(7):1075-1087. doi:10.1617/s11527-012-9954-7

31. Nguyen QT, Di Benedetto H, Sauzéat C, Tapsoba N (2013) Time temperature superposition principle validation for bituminous mixes in the linear and nonlinear domains. J Mater Civ Eng 25(9):1181-1188. doi:10.1061/ (ASCE)MT.1943-5533.0000658

32. Tapsoba N, Sauzéat C, Di Benedetto H, Baaj H, Ech M (2014) Behavior of asphalt mixtures containing RAP and shingles. Road Mater Pavement Des 15(2):330-347. doi:10. 1080/14680629.2013.871091

33. Delaporte B, Di Benedetto H, Chaverot P, Gauthier G (2007) Linear viscoelastic properties of bituminous materials: from binders to mastics. J Assoc Asphalt Paving Technol 76:455-494

34. Delaporte B, Di Benedetto H, Chaverot P, Gauthier G (2009) Linear viscoelastic properties of bituminous materials including new products made with ultrafine particles. Road Mater Pavement Des 10(1):7-38

35. Mangiafico S, Di Benedetto H, Sauzéat C, Olard F, Pouget S, Planque L (2013) Influence of RAP content on complex modulus of asphalt binder blends and corresponding mixes: experimental results and modelling. Road Mater Pavement Des 14(Suppl. 1):132-148

36. Mangiafico S, Di Benedetto H, Sauzéat C, Olard F, Pouget S, Planque L (2014) New method to obtain viscoelastic properties of bitumen blends from pure and RAP binder constituents. Road Mater Pavement Des 15(2):312-329

37. Olard F, Di Benedetto H (2003) General "2S2P1D" model and relation between the linear viscoelastic behaviors of bituminous binders and mixes. Road Mater Pavement Des 4(2):185-224

38. Tiouajni S, Di Benedetto H, Sauzeat C, Pouget S (2011) Approximation of linear viscoelastic model in the 3 dimensional case with mechanical analogues of finite Size. Road Mater Pavement Des 12(4):897-930. doi:10.3166/ RMPD.12

39. Ferry JD (1980) Viscoelastic properties of polymers, 3rd edn. Wiley, New York 